\title{
Adversity Quotient for Prospective Higher Education
}

\author{
Hema G. ${ }^{1}$, Dr. Sanjay M. Gupta ${ }^{2}$
}

\section{ABSTRACT:}

The present research was conducted to understand the Adversity Quotient (AQ) of students who are going to enter into higher education. Higher secondary is the stage from where they move from school to higher education. So, the present research was conducted to study the AQ of 11th standard, English medium school students in Gandhinagar city, Gujarat with reference to various variables. The study was conducted on a sample of 461 boys and girls of $11^{\text {th }}$ standard school students from Gujarat State Board of Education (GSEB) and Central Board of Secondary Education (CBSE) schools. A self-constructed AQ scale was used to collect data from the students. The collected data was analyzed using statistical techniques like mean, SD and C.R values. Result revealed that there was no significant difference in the mean scores of AQ on the basis of gender, stream of education i.e. Commerce, Science and Arts, and various family variables like nature of the family, size of the family, qualification of parents, parents' working status and parents' occupation. However, a significant difference was found in the mean scores of AQ of students on the basis of board of School i.e. GSEB and CBSE. The present study concludes that AQ is not influenced by gender, stream of education and family factors, rather it was seen to be influenced by the type of schools. Investigator inquired and understood the AQ profile of higher secondary school students as it is the gate way to higher Education. By understanding the AQ levels of students, the faculty and staffs can be better equipped to support students as they navigate the stressors of college life.

Keywords: Adversity Quotient (AQ), Gujarat State Board of Education (GSEB), Central Board of Secondary Education (CBSE)

In the past few decades, much attention was given to Intelligence quotient and Emotional quotient, which were believed to be determinants of success and excellent performance in higher education and professional studies. Previous studies in Adversity Quotient (AQ) revealed that some individuals possess a high IQ and all the components of EQ, yet they fail to be successful. Hence, we can understand that, neither IQ nor EQ found to determine one's success, although both play a role. Therefore, it is unanswered yet that how some people endure while some may be equally brilliant and well-adjusted may fail and quit. Thus, here comes a new concept, which is AQ, which is the lifelong ascendant to every individual.

${ }^{1}$ Department of Education, Kadi Sarva Vishwavidyalaya, Sector 23, Gandhinagar, Gujarat ${ }^{2}$ Department of Education, Kadi Sarva Vishwavidyalaya, Sector 23, Gandhinagar, Gujarat 
Stoltz (2000) has introduced the new and interesting concept AQ, which tells how well one withstands adversity and his ability overcome it. Currently, AQ seems to be the missing factor for success in one's life. Today AQ becomes more and more important as the daily dose of adversity rises. Therefore we can understand that, EQ shows way for happy and contented life, whereas, AQ shows how to lead life even in unfavorable adverse situations.

Nowadays, life is a mixture of all sorts of situations. On one hand, there is widening of knowledge, technology and educational revolution and progress, and on the other hand we see unfavorable conditions like poverty, scarcity of resources and increase in social and political problems etc. All these adverse situations created life miserable not only for adults, but also for students. In the last decade in all over the world, it has been witnessed the problems of drug abuse, teenage pregnancy, suicides, rapes, depression, assaults, dropping out of school etc.,(Stolt1997). These situations are the challenges that the students face today. These challenges are referred as adversities.

Adversity involves exposure to unfavourable or calamitous circumstances like cyclone, earthquake or could be hardship faced by the individual at home or workplace. In case of students, adversities include various hardships in society; peer pressure, unfavourable organizational climate, poor social relationship at home, gender discrimination, disordered family environment, loneliness etc., (Nikam and Uplane, 2013). All age groups of students face different sorts of adverse situations. The level of adversity influences the personal and professional life of learners thus manifesting varied consequences on their life. After school education, higher education is another milestone for every individual to succeed. Students are confronted with varied situations during their higher education which are very different from their high school life. Youths, the College or University students are the hope of society's tomorrow, and its future. Hence, it is an alarming situation to address the problems of the students and important to note that students are under various stresses and they are facing through lot of adverse situations at school, home and with peer group.

The study aimed at higher secondary school students as higher secondary education is the foundation of any higher education they are going to choose in future. Higher education aims for the all round development of undergraduates, where it needs the quality oriented education. Evidently, the focus of the effort of colleges was to strengthen college students' comprehensive literacy. The psychological quality is an important part of comprehensive quality, that is, whether the college students have good psychological quality, especially the coping ability against adversity or resilience (bouncing back to normal) in hardship. This inability of coping to any hardship will affect their life and their future development, and also affect whether they can become the qualified builders and trustworthy successors for the cause of society. Higher education with a task of preparing leaders for an uncertain and changing future, need to provide their students the most fundamental trait resilience, to face the inevitable challenges and adversities found across all professions.

According to Paul Stoltz (2000), AQ is the science of human resilience, i.e capacity of people to cope with stress and adversity. AQ can also be referred as the ability of the person to adapt well to stress, adversity, trauma or tragedy. People who apply AQ perform optimally while 
facing adversity. Actually, they not only learn from these challenges but also respond to them healthier and more rapidly. An individual style of responding to adverse situations was measured by AQ.

\section{Adversity Quotient}

AQ is an emerging conceptual framework for understanding and enhancing all facets of success; a measure of how one responds to adversity that can be understood, altered, calculated and interpreted. It is therefore, a scientifically-grounded set of tools for improving response to adversity resulting in an overall effectiveness in personal and professional life. AQ has its origin from three major science fields which are psychoneuroimmunology, neurophysiology, and cognitive psychology. Based on the level of AQ the individuals can be classified as Quitters, Campers and Climbers. AQ was discovered by Stoltz (1997), to be an indicator in achieving success rather than Intelligence quotient and Emotional quotient.

AQ includes following 4 components i.e. Control, Ownership, Reach and Endurance.

1. Control: The degree of control the person perceives that he or she has over adverse events

2. Ownership: The extent to which the person owns or takes responsibility for the outcomes of adversity or the extent to which the person holds himself or herself accountable for improving the situation

3. Reach: The degree to which the person perceives good or bad events reaching into other areas of life

4. Endurance: The perception of time over which good or bad events and their consequences will last or endure

\section{Overview of Related Researches}

Following are the major findings of the previous researches on AQ:

In a study, it was revealed that adversity affects school climate and teacher effectiveness (Chauvin, 1992). In a study conducted by Williams (2003), it was found that adversity was both general and specific and that it could be person-specific or context-specific, and it can range from the micro level (specific school) to the macro level (an entire school district or nation). Regarding gender, it was found that 'Males have higher control over adversity with stronger analytical capability than females [Madelin, (2001); Rodgers et., al (2003)]. According to Shen (2014), androgynous subjects have higher scores of AQ. A study conducted in college students revealed that no significant difference in AQ between male and female students (Flejoles and Muzones, 2009). It was found that there was a positive correlation between AQ and school performance, implying that an increase in AQ scores will increase school performance scores, also indicating that an increase in the ability to handle adversities corresponds to better performance in academics (D'souza, 2006). In a study conducted by Huijan (2009), in college students revealed a significant relationship between AQ and academic performance and also showed that there is a significant difference found in the AQ of the respondents when the group was tested according to course and year level. In various studies, it was revealed that the adversity quotient enhancement programme was significantly effective in secondary school students (Devakumar, 2012), standard VIII students (Priyanka Jain, 2013), in junior college 
students (Almeida, 2009), college students (Enriquez, 2009), and in management students (Sachdev Priti, 2009).

\section{Rationale of the Study}

Higher secondary school education is the foundation of any higher education. Scope of education is broadening, and, need of society and developmental challenges of society are to be met. Who will do all that? If we say higher education learners are responsible to bring about these changes, when will they be able to do? If they are shaped / prepared / groomed, they will face the upcoming challenges / adversities. Higher Education learners could be able to face any situation because one of the most important determinants of success is to cope up with adverse conditions. This study may serve as an initial research that paves the way for researches to understand the AQ of learners which is the gate way for success. By understanding the AQ levels of students, the faculty and staffs can be better equipped to support students as they navigate the stressors of college life. All these aspects motivated the researcher to conduct research in this area. Thus, the researcher felt the need to understand the present status of AQ among higher secondary school students as they are going to enter into higher education where it focuses on all-round development of an individual.

\section{OBJECTIVES}

Following are the objectives outlined for the present study:

1. To study the levels of AQ of $11^{\text {th }}$ standard students

2. To compare the levels of AQ of $11^{\text {th }}$ standard students with reference to gender

3. To compare the AQ of GSEB and CBSE $11^{\text {th }}$ standard students

5. To compare the AQ of Commerce, Science and Arts $11^{\text {th }}$ standard students

6. To compare the AQ of $11^{\text {th }}$ standard students on various family factors

\section{HYPOTHESES}

Based on the objectives of the study, the researcher formulated the following null hypotheses to obtain findings for the present study.

1. There is no significant difference in the mean scores of AQ of boys and girls students.

2. There is no significant difference in the mean scores of AQ of GSEB and CBSE school students.

3. There is no significant difference in the mean scores of AQ of commerce and science students.

4. There is no significant difference in the mean scores of AQ of commerce and arts students.

5. There is no significant difference in the mean scores of AQ of arts and science students.

6. There is no significant difference in the mean scores of AQ of students belonging to joint and nuclear family.

7. There is no significant difference in the mean scores of AQ of students having family size less than or equal to four members and greater than four members. 
8. There is no significant difference in the mean scores of AQ of students whose parents are graduate and non-graduate.

9. There is no significant difference in the mean scores of AQ of students whose both parents are working and one parent is working.

10. There is no significant difference in the mean scores of AQ students whose parents' occupation is service and non-service.

\section{Delimitations of the Study}

The present study was delimited to standard 11, English medium school students of GSEB and CBSE board of Gandhinagar city.

\section{Operational Definitions of Key Terms}

Adversity Quotient: AQ refers to the ability of an individual to handle unpleasant or adverse situations. Based on the scores obtained on the four components (control, ownership, reach and endurance) of AQ inventory, individuals are classified as people with high, moderate and low AQ. Scores obtained on self-constructed AQ scale is considered as AQ.

Stream of Education: Stream of education was divided into Commerce, Science and Arts.

Nature of Family: Nature of family refers to whether the student is staying in Joint family or Nuclear family.

Type of Family: Type of family refers to the members of the family i.e less than or equal to four members and more than four members in the family.

Qualification of Parents: Qualification of parents was divided into graduated parents and nongraduated parents. Graduated parents means one or both of the parents of the students were graduate and more qualified. Non-graduated parents mean none of the parents of the students were graduated.

Parents' working status: Parents working status was divided into both working and single working. Both working means both father and mother of the student is working and single working means any one of the parent is working for their livelihood.

Parents' occupation: Parents occupation is divided into service and non-service. Service means parents who are serving in any government or private organizations. Non-service refers to all other occupations including business, professional etc.,.

\section{Variables of the Study}

The variables included in the present study were as given below:

\section{a. Independent Variables:}

1. Gender - Male and Female

2. Type of School - GSEB and CBSE

3. Stream of Education - Commerce, Science and Arts

4. Nature of Family - Joint and Nuclear 
5. Type of Family - </= 4 members and $>4$ members

6. Parents' Qualification - Graduates and Non-Graduates

7. Parent's Working Status - Both parent and Single Parent]

8. Parent's Occupation - Service and Non-Service

b. Dependent Variable: Adversity Quotient

\section{Research Method}

The study was a descriptive type of survey research because in this study investigator analyzed about the current status of AQ of 11th standard school students.

\section{Population and Sample}

The population of the present study encompasses the students of 11th standard, English medium, GSEB and CBSE schools of Gandhinagar city. Simple random sampling technique was used for the selection of schools and cluster sampling technique was used for selection of students. There were total of 18 higher secondary English medium schools in Gandhinagar city which includes 11 GSEB and 7 CBSE schools out of which 3 GSEB and 2 CBSE schools were selected as sample. Lottery method was used to identify proportionate numbers of schools from all the higher secondary schools in Gandhinagar city.

\section{Research Tool}

The researcher developed a self-constructed AQ scale with 5 point scale. The scoring was 5 to 1 for strongly agree to strongly disagree for each statement. This inventory was constructed based on the components of AQ i.e. control, ownership, reach and endurance.

1 Construction of tool: In construction of the tool, the researcher initiated with analyses of the content area about the AQ, and then items were constructed for assessment of various components of AQ. After preparing the first draft of the tool, it was given for experts' feedback and based on their feedback and suggestions. AQ scale was given to a total of 8 experts including school teachers, teacher educators. Based on the suggestions given, necessary editing was done and it was finalized after pre-piloting. To finalize the items in the scale, piloting and item analysis was done in 151 students of $11^{\text {th }}$ standard. The initial scale in piloting procedure contained 55 items. Following item analysis, based on the computed t value for significant level for each item, only 38 items were selected for the final AQ scale. Total scores of the scale ranged from 38 to 190 .

\section{Data Collection}

After the prior permission of the school authorities, data was collected from 5 schools which included 3 GSEB schools and 2 CBSE schools. In the present research, sample of 461 (270 boys and 191 girls) 11th standard school students, from five schools (3 GSEB and 2 CBSE) were selected. 


\section{DATA ANALYSIS AND INTERPRETATION}

\section{Data Analysis: Objective - 1}

The first objective of the present study was to study the levels of AQ of 11th standard students. The responses of the students against the self-constructed AQ scale were assessed and presented below.

Table.1 Levels of Adversity Quotient in terms of Mean Scores and Percentage of Mean Scores

\begin{tabular}{|l|l|l|l|}
\hline $\begin{array}{l}\text { Adversity Quotient } \\
\text { Levels }\end{array}$ & $\begin{array}{l}\text { Percentage of } \\
\text { Students }\end{array}$ & $\begin{array}{l}\text { Mean Scores } \text { of } \\
\text { Scores }\end{array}$ \\
\hline High AQ & 15.87 & 168.79 & 88.84 \\
\hline Average AQ & 68.26 & 151.76 & 79.87 \\
\hline Low AQ & 15.87 & 126.97 & 66.83 \\
\hline
\end{tabular}

It was found from table 1 that the students showed various levels of AQ. The levels of AQ were determined by the assumptions of normal probability curve. In terms of percentage of mean scores of AQ, 88.84\% scores fall under high AQ level, 79.87\% scores fall under average AQ level and $66.83 \%$ scores fall under low AQ level. The mean scores of total sample was found to be 150.53. The Graph 4.1 indicated the various levels of AQ in terms of percentage of mean scores of AQ.

\section{Data Analysis: Objective - 2}

Data Analysis of Hypothesis 1

The null Hypothesis 1 was tested using C.R values statistically. The following table 2 indicates the findings of this hypothesis.

Table .2 Comparison of Adversity Quotient of Boys and Girls in terms of Mean, S.D., and C.R Values

\begin{tabular}{|l|l|l|l|l|l|l|}
\hline Gender & N & Mean & S.D. & SE $_{\mathbf{D}}$ & C.R Value & Remark \\
\cline { 1 - 4 } Boys & 270 & 149.65 & 14.31 & 1.31 & 1.64 & $\begin{array}{l}\text { Not Significant } \\
\text { at 0.05 level }\end{array}$ \\
\cline { 1 - 4 } Girls & 191 & 151.79 & 13.45 & & & \\
\hline
\end{tabular}

It was found from the table 2 , that the calculated C.R value was 1.64 , whereas the table C.R value was 1.96 at 0.05 level for $\mathrm{df}=459$. The calculated C.R value was found to be less than the table C.R value at 0.05 level. Hypothesis 1 was not rejected as the calculated C.R value was not found to be significantly higher than the table value at 0.05 level. Thus, it indicated that no 
significant difference was found in AQ levels of boys and girls and it can be said that there was no real difference between boys and girls in AQ.

\section{Data Analysis: Objective - 3}

Data Analysis of Hypothesis 2

The null hypothesis 2 was analyzed using C.R values. The following table 3 indicates the findings of this hypothesis.

Table.3 Comparison of Adversity Quotient of GSEB and CBSE students in terms of Mean, S.D., and C.R Values

\begin{tabular}{|l|l|l|l|l|l|l|}
\hline $\begin{array}{l}\text { Type of } \\
\text { School }\end{array}$ & N & Mean & S.D. & $\mathbf{S E}_{\mathbf{D}}$ & C.R Value & Remark \\
\cline { 1 - 2 } & 242 & 152.05 & 14.20 & 1.29 & 2.46 & $\begin{array}{l}\text { Significant at } \\
0.05 \text { level }\end{array}$ \\
\hline CBSE & 219 & 148.86 & 13.58 & & & \\
\hline
\end{tabular}

From table 3 it was found that, the calculated C.R value was 2.46, whereas the table value was 1.96 at 0.05 level for $\mathrm{df}=459$. The calculated C.R value was found to be higher than the table value at 0.05 level. Hence the hypothesis 2 was rejected as there was significant difference found between the levels of AQ on the basis of Board of schools. It means there was significant difference found between students of GSEB and CBSE in AQ scores. The AQ levels of GSEB were higher than CBSE students. Thus, we can conclude that GSEB students were better in managing adversity than the CBSE students.

\section{Data Analysis: Objective - 4 \\ Data Analysis of Hypothesis 3}

The null hypothesis 3 analyzed using C.R values. The following table 4 shows the analyses of this hypothesis

Table .4 Comparison of Adversity Quotient of Commerce and Science students in terms of Mean, S.D., and C.R Values

\begin{tabular}{|l|l|l|l|l|l|l|}
\hline $\begin{array}{l}\text { Stream of } \\
\text { Education }\end{array}$ & $\mathbf{N}$ & Mean & S.D. & $\mathbf{S E}_{\mathbf{D}}$ & C.R value & Remark \\
\cline { 1 - 1 } Commerce & 161 & 150.00 & 15.27 & 1.45 & 0.79 & $\begin{array}{l}\text { Not Significant } \\
\text { at } 0.05 \text { level }\end{array}$ \\
\hline Science & 266 & 151.16 & 13.26 & & & \\
\hline
\end{tabular}

It was found from the table 4 , that the calculated C.R value was 0.79 , whereas the table value was 1.96 at 0.05 level for $\mathrm{df}=425$. The calculated C.R value was found not significantly higher 
than the table value at 0.05 level. Hence, Hypothesis 3 was not rejected as there was no significant difference found in AQ levels of commerce and science students. Thus, it can be said that there was no real difference between boys and girls in AQ.

\section{Data Analysis of Hypothesis 4}

The null hypothesis 4 was tested and data was analyzed and interpreted in the following table 5 as below.

Table .5 Comparison of Adversity Quotient of Commerce and Arts students in terms of Mean, S.D., and C.R Values

\begin{tabular}{|l|l|l|l|l|l|l|}
\hline $\begin{array}{l}\text { Stream of } \\
\text { Education }\end{array}$ & $\mathbf{N}$ & Mean & S.D. & SE $_{\mathbf{D}}$ & C.R value & Remark \\
\cline { 1 - 3 } & 161 & 150.00 & 15.27 & 2.55 & 0.74 & $\begin{array}{l}\text { Not Significant } \\
\text { at } 0.05 \text { level }\end{array}$ \\
\hline Arts & 34 & 148.11 & 13.11 & & & \\
\hline
\end{tabular}

It was found from table 5 that the calculated C.R value was 0.74 , whereas the table value was 1.97 at 0.05 level for $\mathrm{df}=193$. The calculated C.R value was found to be less than the table value at 0.05 significant level. Therefore, the hypothesis 4 , was not rejected as there was no significant difference in the AQ of Commerce and Arts students. Thus, it was drawn that the AQ level was not significantly different in Commerce and Arts students.

\section{Data Analysis of Hypothesis 5}

The null hypothesis 5 was tested using C.R values. The data were presented in the following table 6 .

Table 6 Comparison of Adversity Quotient of Arts and Science students in terms of Mean, S.D., and C.R Values

\begin{tabular}{|l|l|l|l|l|l|l|}
\hline $\begin{array}{l}\text { Stream of } \\
\text { Education }\end{array}$ & $\mathbf{N}$ & Mean & S.D. & SE $_{\mathbf{D}}$ & C.R value & Remark \\
\hline Arts & 34 & 148.11 & 13.11 & 2.39 & 1.27 & $\begin{array}{l}\text { Not Significant } \\
\text { at 0.05 level }\end{array}$ \\
\cline { 1 - 3 } Science & 266 & 151.16 & 13.26 & & & \\
\hline
\end{tabular}

It was found from table 6 , that the calculated C.R value was 1.27 , whereas the table value was 1.97 at 0.05 level for $\mathrm{df}=293$. The calculated C.R value was found to be not significantly higher than the table value at 0.05 level. Hence, it was inferred that there was no significant difference in the AQ of Arts and Science students. Thus, the hypothesis 5 was not rejected as there was no real difference in the AQ levels of Arts and Science students. 


\section{Data Analysis: Objective - 5 \\ Data Analysis of Hypothesis 6}

The null Hypothesis 6 was tested using C.R values statistically. Following table 7 depicts the analysis of this hypothesis.

Table .7 Comparison of Adversity Quotient of Joint and Nuclear Family students in terms of Mean, S.D., and C.R Values

\begin{tabular}{|c|c|c|c|c|c|c|}
\hline $\begin{array}{l}\text { Nature of } \\
\text { Family }\end{array}$ & $\mathbf{N}$ & Mean & S.D. & $\mathbf{S E}_{\mathbf{D}}$ & C.R Value & Remark \\
\hline Joint & 147 & 150.75 & 14.89 & \multirow[t]{2}{*}{1.45} & \multirow[t]{2}{*}{0.22} & \multirow[t]{2}{*}{$\begin{array}{l}\text { Not Significan } \\
\text { at } 0.05 \text { level }\end{array}$} \\
\hline Nuclear & 314 & 150.43 & 13.56 & & & \\
\hline
\end{tabular}

It was evident from table 7 that the calculated C.R value was 0.22 , whereas the table value was 1.96 at 0.05 level for $\mathrm{df}=459$. From the data it was drawn that there was no significant difference found in the AQ levels of students in joint and nuclear family. Thus, the hypothesis 6 was accepted as there was no significant difference in AQ levels on the basis of nature of family. Thus it can be said that there was no real difference in the mean AQ scores of students belonging to joint family and nuclear family.

\section{Data Analysis of Hypothesis 7}

The null Hypothesis 7 was analyzed with the help of C.R values. Data was presented in the following table 8 .

Table .8 Comparison of Adversity Quotient of students on the Basis of Types of Family in terms of Mean, S.D., and C.R Values

\begin{tabular}{|l|l|l|l|l|l|l|}
\hline Types of Family & $\mathbf{N}$ & Mean & S.D & SE $_{\mathbf{D}}$ & $\begin{array}{l}\text { C.R } \\
\text { value }\end{array}$ & Remark \\
\hline $\begin{array}{l}\text { Family size }</=4 \\
\text { members }\end{array}$ & 266 & 150.58 & 14.18 & \multirow{2}{*}{1.31} & 0.088 & $\begin{array}{l}\text { Not } \\
\text { Significant } \\
\text { at } 0.05 \\
\text { level }\end{array}$ \\
\hline Family size > 4 members & 195 & 150.47 & 13.75 & & & \\
\hline
\end{tabular}

It was found from the table 8 , that the calculated C.R value was 0.088 , whereas, the table value was 1.96 at 0.05 level for $\mathrm{df}=459$. Hence, calculated C.R value was not significantly higher than the table value. From the data, it was drawn that there was no significant difference in the AQ levels between the above two groups. Thus, the hypothesis 7 was not rejected as there was no difference found in the AQ level in students belonging to family size less than or equal to four members and greater than four members. It can be said that there was no real difference found in the AQ levels of the students on the basis of types of family. 


\section{Data Analysis of Hypothesis 8}

The null hypothesis 8 was tested with the help of C.R value and the data was depicted as followed in table 9.

Table.9 Comparison of Adversity Quotient of students on the Basis of Qualification of Parents in terms of Mean, S.D., and C.R Values

\begin{tabular}{|l|l|l|l|l|l|l|}
\hline $\begin{array}{l}\text { Parents' } \\
\text { Qualification }\end{array}$ & N & Mean & S.D. & SE $_{\mathbf{D}}$ & C.R value & Remark \\
\hline Graduates & 339 & 150.61 & 14.15 & 1.45 & 0.19 & $\begin{array}{l}\text { Not } \\
\text { Significant } \\
\text { at 0.05 level }\end{array}$ \\
\hline Non-Graduates & 122 & 150.33 & 13.56 & & & \\
\hline
\end{tabular}

From table 9, it was found that the calculated C.R value was 0.19 , whereas, the table value was 1.96 at 0.05 level for $\mathrm{df}=459$. The calculated C.R value was found to be not significantly higher than the table value at 0.05 level. Hence, it was inferred that there was no significant difference in the AQ of students based on their parents' qualification. Thus, the hypothesis 8 was not rejected as there was no significant difference in the mean scores of AQ of the students whose parents were graduated and non-graduated. It means that there was no real difference found between the above two groups in the levels of AQ.

\section{Data Analysis of Hypothesis 9}

The null hypothesis 9 was tested and the data was analyzed with the help of C.R value and depicted as following in table 10 .

Table .10 Comparison of Adversity Quotient of students on the Basis of Working Status of Parents in terms of Mean, S.D., and C.R Values

\begin{tabular}{|l|l|l|l|l|l|l|}
\hline $\begin{array}{l}\text { Parents' Working } \\
\text { Status }\end{array}$ & N & Mean & S.D. & SE $_{\mathbf{D}}$ & t-value & Remark \\
\hline Single & 379 & 150.89 & 13.78 & 1.79 & 1.15 & $\begin{array}{l}\text { Not Significant } \\
\text { at 0.05 level }\end{array}$ \\
\hline Both & 82 & 148.84 & 14.86 & & & \\
\hline
\end{tabular}

It was found from table 10, that the calculated C.R value was 1.15 whereas, the table value was 1.96 at 0.05 level for $\mathrm{df}=549$. Hence, the calculated C.R value was less than the table value, it was inferred that there was no significant difference in the AQ of students whose both parents are working and one parent is working. Thus, the hypothesis 9 was accepted. And it can be said that there was no real difference found in the AQ between the students' whose both parents are working and one parent is working. 


\section{Data Analysis of Hypothesis 10}

The Null Hypothesis 10 was tested and the data was analyzed statistically and depicted in table 11.

Table .11 Comparison of Adversity Quotient of students on the Basis of Occupation of Parents in terms of Mean, S.D., and C.R Values

\begin{tabular}{|l|l|l|l|l|l|l|}
\hline $\begin{array}{l}\text { Parents' } \\
\text { Occupation }\end{array}$ & $\mathbf{N}$ & Mean & S.D. & $\mathbf{S E}_{\mathbf{D}}$ & C.R value & Remark \\
\hline Service & 258 & 150.58 & 13.24 & 1.33 & 0.08 & $\begin{array}{l}\text { Not Significant } \\
\text { at } 0.05 \text { level }\end{array}$ \\
\hline Non-service & 203 & 150.47 & 14.90 & & & \\
\hline
\end{tabular}

From table 11, it was found that the calculated C.R value was 0.08 whereas, the table C.R value was 1.96 at 0.05 level for $\mathrm{df}=459$. The computed C.R value was found to be not significantly higher than the table value at 0.05 level. Hence, it was predicted that there was no significant difference in the AQ of students based on their parent's occupation. Thus, the hypothesis 10 was not rejected as there was no significant difference in the mean scores of the AQ of the students whose parent's occupation is service and non-service. It means that there was no real difference in AQ levels of students on the basis of their parents' occupation.

\section{MAJOR FINDINGS}

Following are the major findings of the study:

1. In the present research, it was found that the mean AQ scores for complete sample was 150.53 , mean for boys was 149.65 and mean for girls was 151.79 .

2. It was found that there was real difference found in the scores of AQ of GSEB and CBSE students. The AQ of GSEB students were found to be higher than CBSE students.

3. From the analysis, it was found that there was no effect of gender, stream of education and family factors such as nature of family (joint and nuclear), type of family (family size $</=4$ members and family size $>4$ members), Parents' Qualification (graduated and nongraduated), Parents' working status (single working and both working) and Parents' occupation (service and non-service), on AQ of 11th standard school students.

\section{DISCUSSION OF THE FINDINGS}

The research of Devakumar M (2012) showed that there was no significant difference in the total AQ scores of students on the basis of school types. However, the studies of Radhika Vakharia (2012), and D'souza, Roschelle P. (2006) revealed that there was a significant difference in the AQ scores across different boards of schools, which was similar to the present findings. In addition, D'souza Roschelle P. (2006) study showed that CBSE students were better in handling adversities compared to State Board school students, which was observed incongruous in the present study; in the present study GSEB students were found to be better in AQ than CBSE students. 
It was found that the level of AQ among the highest percentage of respondents was below average according to Cura, J., \& Gozum, J. (2011). It was also found from the same study that the AQ of the respondents was not influenced by their sex, course, academic status, scholastic status, scholarship grant and the type of high school they graduated. The age and gender difference did not affect the AQ according to Cornista, G., \& Macasaet, C. (2013). According to Huijuan, Z. (2009) study, the AQ of students was not influenced by gender. All these previous findings supported the present research findings. However, a study conducted by Liu, L. (2011) showed that different gender roles had significant difference in AQ which was differing to the previously discussed studies and the findings of the present study.

AQ of students was found to be in relation with course and year level according to Huijuan, Z. (2009), however, in the present study, it was found that there was no significant effect of stream of education on AQ of students.

\section{EDUCATIONAL IMPLICATIONS}

There are several implications that can be drawn from the present research, to inform practice for the various stakeholders in the educational fraternity.The present study gave an understanding to the students regarding their adverse situations and their level of AQ which consequently can help them in identifying what can be done to enhance their AQ at personal level and professional level. The research gave knowledge to various educational personnels about the AQ levels in students and guided them to make remedial measures if necessary and make classroom activities meaningful and relevant to students' lives, culture, and future. Also, the higher education institutions could plan for remedial programmes at the entry level, which consequently lead to strong higher educational outcomes. In addition to this, higher education can provide programmes and workshops on idol inspirations, know yourself- group activity, LEAD yourself-group activity etc., to enhance the adversity quotient levels of the students. It will provide an insight to the college management and authorities, on the urgency in the need to organize such seminars and workshops to develop the all-round skills of students in order to be able to handle adversities that continuously surround them in today's stress busted times. A more comprehensive curriculum can be designed by the curriculum developers and governance strategies can be developed by understanding the AQ levels of the students. Education curriculum should be based on real life situations. It should be prepared in such a way that it orients the learners to face the upcoming difficulties. This may help them to be successful in life. CBSE Board should analyze the curriculum and try to provide more inputs that enhance the AQ of learners. Based on this research findings their objectives can be aligned with the changing trends and meet the needs of the students in changing times with respect to the challenges and hardships the future holds. Education system should identify AQ of higher education learners at entry level and customized inputs are to be offered to enhance their AQ. Schools and college teachers should study the environment more minutely and plan learning experiences accordingly. This study emphasizes the need to appoint counselors in colleges and help the counselors to enable the students to know their weaknesses and develop them into their strengths by providing them vocational, educational and personal guidance. Although personal variables are found not 
affecting the AQ, more studies are to be conducted to explore and confirm these variables effect on AQ in future. If effect of family may appear in future due to uncertain and changing family environment, parenting education should be provided to parents.

\section{SUGGESTIONS FOR FUTURE RESEARCH}

Following are the suggestions made for future researchers:

- The research can further be done at primary and secondary school level.

- Comparison between CBSE, GSEB and ICSE school Boards can be done.

- A standardized tool for measuring AQ in Indian Context is not available yet. Therefore, AQ scale can be constructed and standardized for higher secondary school students.

- AQ of students living with family and in hostel can be studied and compared.

- AQ of students belonging to rural and urban area can be studied.

- AQ of government schools and private schools can be studied.

- Comparison of AQ of students belonging to different states of India can be done.

- AQ enhancing programmes can be developed and experimental research can be done.

- Different components of AQ can be studied and compared. Different AQ enhancing programmes can be developed for specific component of $A Q$.

- The present research is the initial study conducted for the first time in Gandhinagar city. Similar research on AQ can be conducted on other districts of Gujarat.

- To confirm the findings of the present study and previous researches, a large sample study can be done to confirm the results.

- Researches on the relationship of AQ with other psychological factors can be done.

\section{CONCLUSION}

The present study was conducted to know the AQ and its relationship with Self-esteem of $11^{\text {th }}$ standard school students of Gandhinagar city in Gujarat. The findings obtained using survey method showed that there was real difference in AQ of students with respect to school types. To the knowledge of the investigator, there were few researches conducted in India, and the present study is the first attempt taken in Gujarat. Considering this fact, the researcher tried to find the knowledge that is useful in the field of education. This attempt of researcher will be considered useful if the findings of the study are used to improve the present scenario of the education system. On the whole, by enhancing the levels of AQ in future citizens of the society, resilient individuals can be given for the National development as whole. This study, have application for thousands of students and educational stakeholders.

\section{REFERENCES}

Almeida, A(2009). Development of a programme for enhancing AQ of Junior College students, Retrieved from http://peaklearning.com/grp research.html 
Cornista, G., \& Macasaet, C. (2012). Adversity Quotient and Achievement Motivation of Third Year and Fourth Year Psychology Students of de la Salle Lipa. Retrieved from http://www.peaklearning.com/documents/PEAK_GRI_cornista-macasaet.pdf

Cura, J., \& Gozum, J. (2011). Correlational Study on Adversity Quotient ${ }^{\circledR}$ and the Mathematics Achievement of Sophomore Students of College of Engineering and Technology in Pamantasan $n g$ Lungsod $n g$ Maynilaw Retrieved from http://www.peaklearning.com/documents/PEAK_GRI_gozum.pdf

Chauvin, S. W. (1992). An exploration of principal change facilitator style, teacher bureaucratic and professional orientations, and teacher receptivity to change. Unpublished doctoral dissertation, Louisiana State University, Baton Rouge, LA

D'souza, R (2006). A Study Of Adversity Quotient Of Secondary School Students In Relation To Their School Performance And The School Climate, Department of Education, University of Mumbai, Unpublished Doctoral thesis Retrieved from www.peaklearning.com/documents/PEAK_GRI_dsouza.pdf

Devakumar, M. (2012). A Study of Adversity Quotient of Secondary School Students in Relation to their Academic Self Concept and Achievement Motivation, Retrieved from http://www.peaklearning.com/documents/PEAK_GRI_devakumar2.pdf

Enriquez, J. (2009). The effect of a mentoring program on the AQs of college freshmen Retrieved from http://www.peaklearning.com/documents/PEAK_GRI_enriquez.pdf

Flejoles and Muzones, (2009). Adversity Quotient of Bachelor of science in maritime information technology students, Maritime University, Molo, Inc., Philippines. Unpublished Doctoral thesis, $\quad$ Retrieved from http://www.academia.edu/3621438/Adversity_Quotient_of_Bachelor_of_Science_in_Mari time_Information_Technology_Students_at_John_B._Lacson_Foundation_Maritime_Univ ersity-Molo_Inc

Huijuan, Z. (2009). $A Q$ and academic performance among college students at St. Joseph College, Department of Psychology, Quezon city, Unpublished Doctoral thesis, Retrieved from www.peaklearning.com/documents/PEAK_GRI_huijuan.pdf

Liu, L. (2011). Men are from mars and women are from venus?"--from the aspect of gender role, the interrelationships between $A Q$, work pressure, personal characteristic, and work performance, Retrieved from http://libserver2.nhu.edu.tw/ETD-db/ETDsearch/view_etd?URN=etd- 1207111-111820

Madelin, B. (2001). Les femmes-relais, les "sans-papiers" du travail social? VEI enjeux, vol.124: pp.81-91.

Nikam and Uplane (2013), Adversity Quotient and Defense Mechanism of Secondary School Students, Universal Journal of Educational Research, Vol. 1 (4), pp. 303-308

Rodgers, B., Blewitt, K., Jacomb, P., \& Rosenman, S. (2003), Child abuse Prevention, Australian Institute of Family studies, Melbourne, Australia: Newsletter, 11(1). 
Sachdev, P. (2011). Effectiveness of an Intervention Programme to Develop Adversity Quotient ${ }^{\circledR}$ of Potential Leaders, Retrieved from http://www.peaklearning.com/documents/PEAK_GRI_pritiSachdev.pdf

Shen Chao-Ying (2014), The relative study of gender roles, and job stress and adversity quotient, The Journal of Global Business Management, 10(1).

Stoltz, P. G. (2000). Adversity Quotient at Work: Make Everyday Challenges the Key to Your Success- Putting the Principles of $A Q$ Into Action. Canada: John Willey and Sons, Inc. Wiley Publishers

Stoltz,P.G(1997) Adversity Quotient- turning obstacles into opportunities, Retrieved from www.peaklearning.com

Vakharia Radhika (2012). A study of secondary school students' response to adversity in relation to certain psychological and performance factors, Retrieved from http://www.peaklearning.com/documents/PEAK_GRI_vakharia2.pdf

Williams Mark (2003). The relationship between principal response to adversity and student achievement Cardinal Stritch University, College of Education in Leadership for the Advancement of Learning and Service, Retrieved from http://peaklearning.com/documents/grp_williams_dissertation.pdf 